\title{
Ants' Capability of Adding Numbers of Identical Elements
}

\author{
Marie-Claire Cammaerts ${ }^{1} \&$ Roger Cammaerts ${ }^{2}$ \\ ${ }^{1}$ Biology of Organisms Department, University of Brussels, Belgium \\ ${ }^{2}$ Natural and Agricultural Environmental Studies Department (DEMNA) of the Walloon Region, Belgium \\ Correspondence: Marie-Claire Cammaerts, Independent Researcher, 27, Square du Castel Fleuri, 1170 Bruxelles, \\ Belgium. Tel: 32-2-673-4969. E-mail: mtricot@ulb.ac.be; mccammaerts@gmail.com
}

Received: April 26, 2019

Accepted: May 17, 2019

Online Published: May 27, 2019

doi:10.5539/ijb.v11n3p25

URL: https://doi.org/10.5539/ijb.v11n3p25

\begin{abstract}
Knowing that the workers of the ant Myrmica sabuleti can distinguish different numbers of elements and have a basic notion of zero, we here examine if they can add two numbers of identical elements seen simultaneously. As soon as after three training days, the ants could respond significantly more to the sum of $1+1,2+1,3+1$, and 3 +2 elements than to the two initial numbers of elements seen during training and to the wrong sums $3,4,5$ and 6 respectively. Their ability in giving the correct response seemed to somewhat decrease with increasing numbers to add. Twenty-four hours after the removal of the initial numbers presented during training, the ants no longer responded essentially to the correct sum of these numbers.
\end{abstract}

Keywords: Cognition, Counting, Learning, Myrmica sabuleti, Sums

\section{Introduction}

The capability of adding numbers of identical elements has been observed in only a few animal species. This capability has been acquired over the animals' evolution, and by individuals in the course of their life. A first step of such an acquisition consists in globally distinguishing different amounts of elements, without counting these elements but ranking the different amounts on an ordinal scale. Such ability is rather common in the animals' kingdom and has been observed, among others, in fishes, birds and mammals (Agrillo, Dadda, Serena, \& Bisazza, 2008; Rugani, Vallortigara, Priftis, \& Regolin, 2015; Range, Jenikejew, Schröder, \& Virányi, 2014; Brannon, Herbert, \& Terrace, 1988). A second step in the acquisition of the adding numbers capability consists in counting the perceived elements for obtaining a precise assessment of their amount. This ability has been observed for instance in male frogs, birds and monkeys (Rose, 2018; Hunt, Low, \& Burns, 2008; Pepperberg \& Gordon, 2005; Xia, Sieman, \& Delius, 2000; Woodruff \& Premack, 1981). Is this ability detained by ants? On the basis of a previous work made on Myrmica sabuleti Meinert 1861 in which we showed that this ant can distinguish different numbers of elements (Cammaerts, 2008), we presumed that some basic counting by ants may occur, at least for small amounts of elements. For checking this presumption, we here aimed to examine if these ants could reach the following third step of the acquisition of a number concept. This third step consists in being able to add or subtract numbers of identical elements, an ability proved to be detained by some birds, monkeys and rats (Rugani et al., 2015; Brannon et al., 1988; Woodruff \& Premack, 1981; Church \& Meck, 1984). The fourth step in the acquisition of a number concept consists in making a correspondence between each number and a symbol, and this, until now, has been shown to be achieved (learned) by chimpanzees (they can acquire a visual representation of the numbers 1 to 9) (Matsuzawa, 2009) and parrots (they can acquire a phonetic representation of the numbers 1 to 9) (Pepperberg, 2006; Hauser, Carey, \& Hauser, 2000).

In the present work, we examine if ants could detain, at least to some extent, the third (and thus a fortiori the second) step of the notion of number of elements. It has been shown that bees have the notion of zero and correctly locate the zero in an increasing as well as in a decreasing series of numbers (Howard, Avarguès-Weber, Garcia, Greentree, \& Dyer, 2018). In ants, besides having pointed out that $M$. sabuleti workers can distinguish different numbers of elements (Cammaerts, 2008), we have also shown that they have a basic notion of zero using their visual as well as their olfactory perception (Cammaerts \& Cammaerts, 2019a, 2019b). Here, we intended to work again on colonies of $M$. sabuleti, presenting them either $1+1$, or $2+1$, or $3+1$, or $3+2$ elements, and looking if they could, each time, add the two presented numbers of elements, i.e. could preferentially react to the sum of these elements (i.e. 2, 3, 4 and 5) instead of to the initial terms or to a wrong sum of them. 


\section{Material and Methods}

\subsection{Collection and Maintenance of Ants}

The experiments have been conducted on 8 colonies of M. sabuleti (labeled A to H) collected in September 2018, in an abandoned quarry of the Aise valley (Ardenne, Belgium) and in June 2018 at Marchin (Condroz, Belgium), also in an abandoned quarry. Each colony contained about 500 workers, brood and a queen. They were maintained in the laboratory in two to three glass tubes half filled with water, a cotton plug separating the ants from the water. The nest tubes of each colony were set in a tray $(34 \mathrm{~cm} \times 23 \mathrm{~cm} \times 4 \mathrm{~cm})$ serving as foraging area. In these trays, pieces of Tenebrio molitor larvae (Linnaeus, 1758) were deposited three times per week, and cotton plugged tubes filled with sugar water were permanently set. The ambient temperature was $c a 20^{\circ} \mathrm{C}$, the humidity $80 \%$, the lighting 330lux while working on ants, and the electromagnetism $2 \mu \mathrm{Wm}^{2}$, optimum environmental conditions for the species. The ants of a same colony are here often named 'nestmates' as researchers on social insects commonly do.

\subsection{Cues Presented to the Ants}

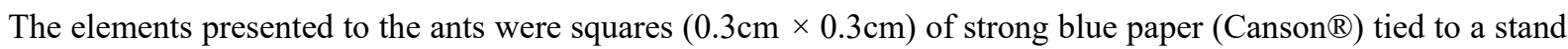
$(2.5 \mathrm{~cm} \times 2.5 \mathrm{~cm})$ made of strong white paper $($ Steinbach $®)$ and maintained vertically thanks to its duly folded horizontal base $(2.5 \mathrm{~cm} \times 0.5 \mathrm{~cm})$ (Figure 1 upper part). The number of elements tied to the stand differed according to the conducted experiment (I to IV; Figure 1 lower part). During the training part of each experiment, two stands with their elements were presented to the ants; during the testing part of these experiments, four stands were presented to the ants. As shown in the lower part of Figure 1, one and the other of the two stands presented during training supported 1 and 1 elements during experiment I, 2 and 1 elements during experiment II, 3 and 1 elements during experiment III, and 3 and 2 elements during experiment IV. During testing, the four stands supported the one and the other numbers of elements presented during training, their sum and their sum plus one element.

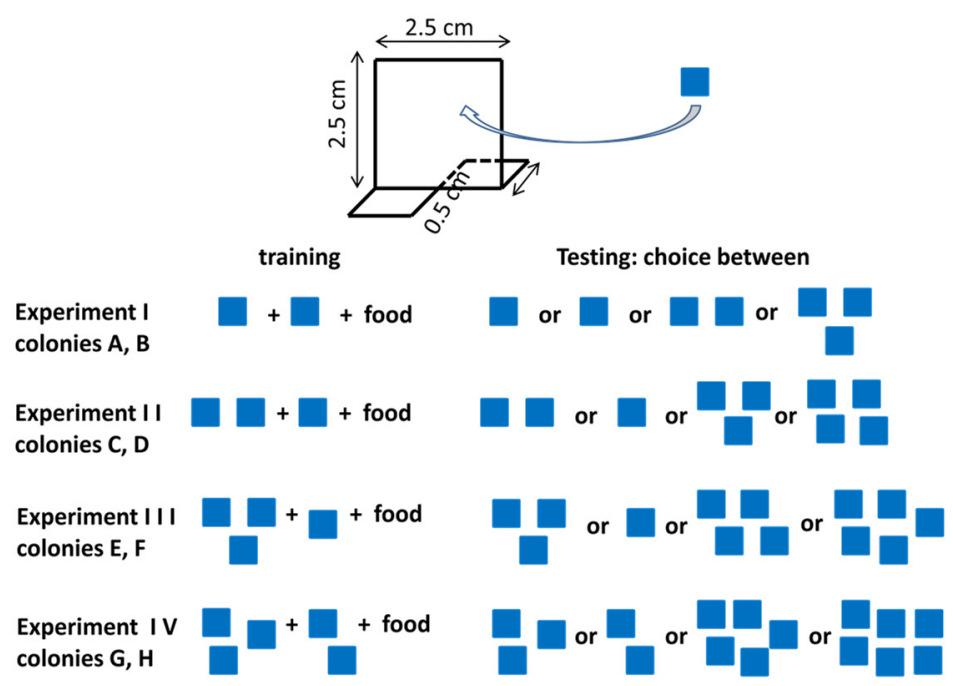

Figure 1. Numbers of elements and their display used to examine if ants could add these numbers The experimental design is shown in Figure 2 and some photos are shown in Figure 3.

\subsection{Experimental Design}

The experiment I was made on colonies A and B, the experiment II on colonies $\mathrm{C}$ and $\mathrm{D}$, the experiment III on colonies $\mathrm{E}$ and $\mathrm{F}$, and the experiment IV on colonies $\mathrm{G}$ and $\mathrm{H}$. Each time, the two stands with their elements were set, at the same time, in the ants' foraging area, the face with the elements turned towards the nest entrance, between the meat and the sugar water food (Figure 2, upper part). Such a presentation to the ants was the ants' training, and lasted 12 days. 


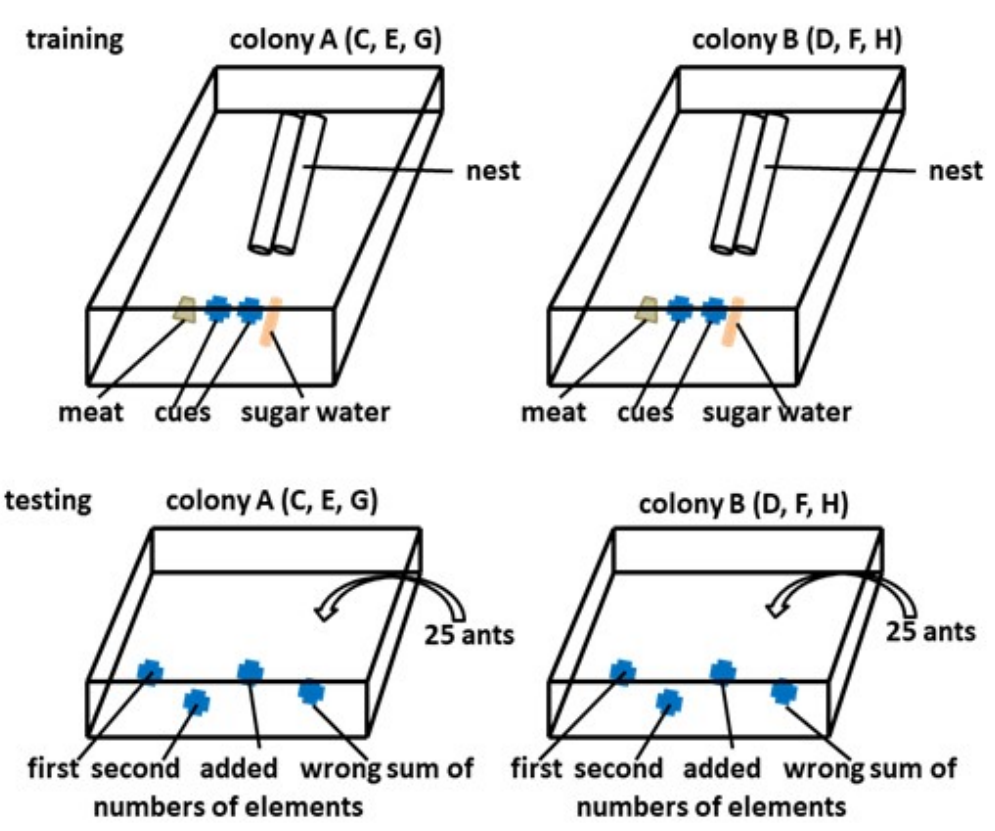

Figure 2. Schematic representation of the design used for knowing if ants could add numbers of elements

These elements are shown in Figure 1 and some photos are shown in Figure 3.

At days 3, 6, 9 and 12 of the 12 training days, the ants of each colony were tested in a separate tray $(30 \mathrm{~cm} \times 15 \mathrm{~cm}$ $\times 4 \mathrm{~cm}$ ) the borders of which having been slightly covered with talc to prevent escaping, and into which having been set the four stands devoted to test, bearing the adequate numbers of elements (Figure 2, lower part). The elements tied to the four stands were the same as those presented during training, their correct sum, and a wrong sum of them. They were thus for the experiments I, II, III, and IV respectively: 1, 1, 2, 3; 2, 1, 3, 4; 3, 1, 4, 5; 3, 2, 5, 6 (Figure 1, lower part).

\subsection{Experimental Protocol}

At each training day, the ants, of each colony surrounding the two presented stands with the elements, were counted six times over the day, and the two mean values were established (Tables 1 to 4 , upper part).

At each testing day (corresponding to days 3, 6, 9 and 12 of training), 25 ants of each colony were transferred into their tray devoted to testing (Figure 2, lower part), and the ants present at a distance of $0-2 \mathrm{~cm}$ from each of the four stands (the two stands bearing the two numbers presented during training, the stand with the correct sum, and the stand with the sum + one more element) set in the tray were counted 20 times over 10 experimental minutes. The means of these counts were established (Tables 1 to 4 , lower part). The proportion of correct responses (= the proportion of ants choosing the correct added number of elements $=$ the number of these ants among the total number of ants seen near all the stands) was calculated for each testing day. These proportions are given in the text, not in a table. The numbers of ants near each kind of stand, obtained during the four testing sessions and totalized, allowed calculating, for each kind of experiment (I to IV), the percentage of responses given to each kind of numbers of elements presented. These percentages are presented in Figure 4.

At the end of each four experiments, the two stands set on the ants' foraging area were removed and the ants tested 24 hours later for assessing their remembering of the learned adding of numbers (if any), a complementary experiment reported only in the text and not in Tables. 


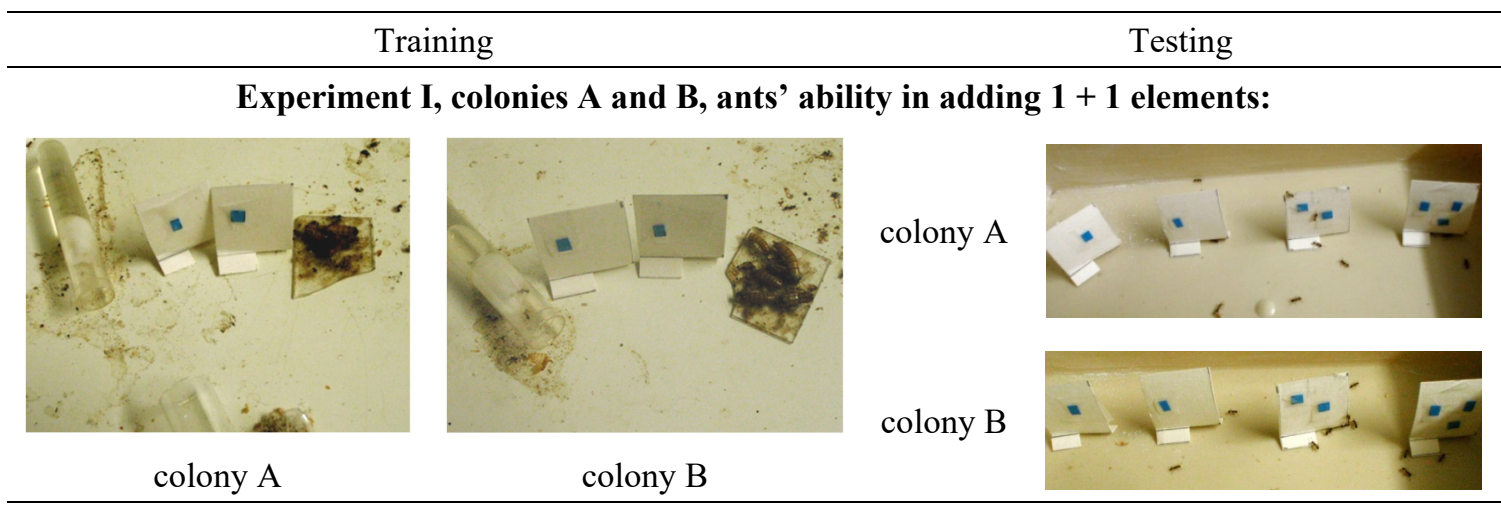

Experiment II, colonies $\mathrm{C}$ and $\mathrm{D}$, ants' ability in adding $2+1$ elements

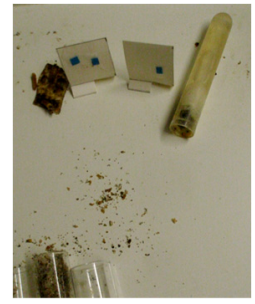

colony $\mathrm{C}$

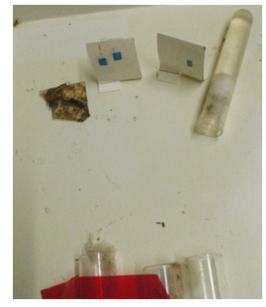

colony D colony $\mathrm{C}$

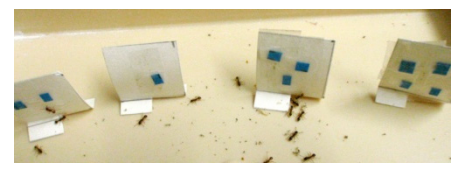

colony D

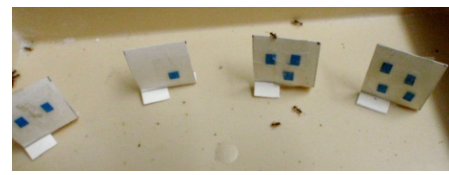

Experiment III, colonies $E$ and $F$, ants' ability in adding $3+1$ elements

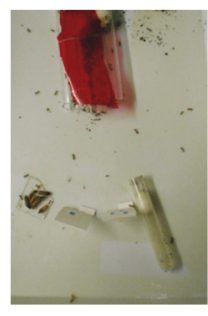

colony E

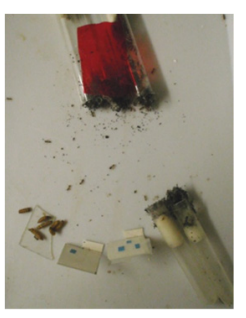

colony $\mathrm{F}$ colony E

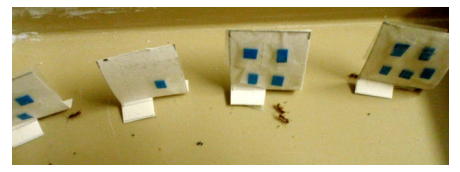

colony $\mathrm{F}$

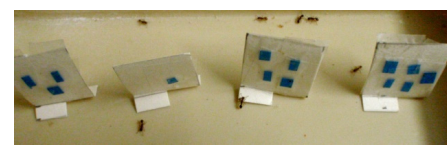

Experiment IV, colonies $G$ and $H$, ants' ability in adding $3+2$ elements

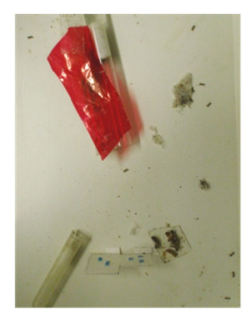

colony $\mathrm{G}$

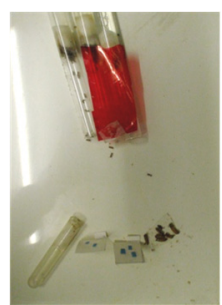

colony $\mathrm{H}$ colony G

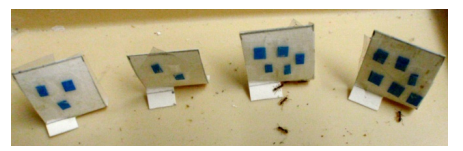

colony $\mathrm{H}$

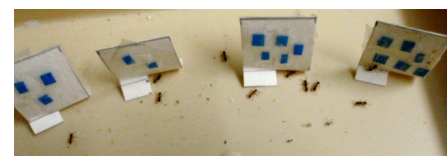

Figure 3. Some photos of the experiments

The numbers of elements presented to the ants are schematized in Figure 1, the experimental design is schematized in Figure 2, and details and statistics are given in the text. Briefly, during experiment $\mathrm{I}$, the ants were more numerous in front of 2 elements, having thus correctly added $1+1$ elements. During experiment II, the ants were more numerous in front of 3 elements, having thus correctly added $2+1$ elements. During experiment III, more ants approached the stand with four elements; they have thus correctly added $3+2$ elements. During experiment IV, more ants came in front of the stand with 5 elements, giving thus the correct response $3+2=5$. 


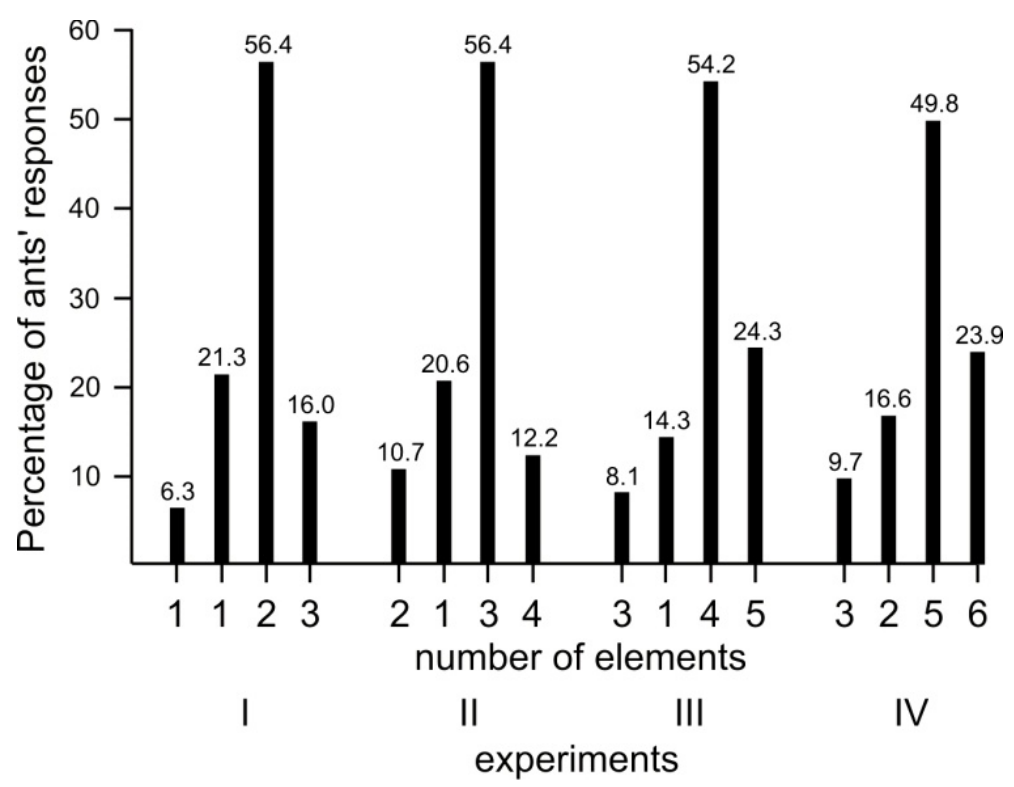

Figure 4. Comparison of the results of experiments I to IV

The numbers of elements presented to the ants and the experimental design are shown in Figures 1 and 2. For each experiment, the ants were trained to two numbers of elements (1 and 1,2 and 1,3 and 1,3 and 2), and then tested in front of these two numbers, their correct sum and a wrong sum. They reacted the best to the correct sum $(2,3,4,5)$, and seemed to do so somewhat less well as the number of elements increased. Accordingly, they also responded somewhat more to the wrong sum of elements $(5,6)$ as the numbers of elements increased.

\subsection{Statistical Analysis}

The data relative to the ants' training did not require any statistical analysis.

Those concerning the ants' testing (i.e. their responses to the four presented numbers of elements) were twice statistically analyzed. First, for each presented number of elements, at each testing day (days 3, 6, 9 and 12), the 20 numbers of ants were chronologically grouped and added by four, and the five sums so obtained (not written in the tables) for each stand could be compared to one another using the non parametric test of Wilcoxon (Siegel \& Castellan, 1989). Secondly, for each experiment (I to IV), the totality of the obtained mean values was statistically analyzed. For each of the four numbers of elements presented to the ants, the eight mean values obtained for the two colonies (2) at each of the four testing days (4) (=8 mean values) were compared to one another using the non-parametric test of Wilcoxon (Siegel \& Castellan, 1989).

\section{Results}

The numerical results of each experiment are given in a separate table and are graphically summarized in Figure 4.

\subsection{Experiment I, Ability in Adding $1+1$ Elements}

During their training, the ants were sufficiently numerous near the two presented stands for progressively memorizing these cues (Table 1, upper part). Indeed, meanly 4.86 of them were usually seen in due place.

As for the testing (Table 1, lower part; Figure 3, upper part), already at day 3, the ants appeared to be more present near the stand bearing 2 elements than near the other stands. Summed by four, the numbers of these ants equaled successively 14, 14, 17, 12 and 16 over the 10 experimental minutes, what statistically differed from the numbers obtained for the stand bearing 1 element and located aside that with 2 elements $(2,3,11,10,8)(\mathrm{N}=5, \mathrm{~T}=+15, \mathrm{P}$ $=0.031)$ and the stand bearing 3 elements $(3,6,5,5,6,9)(\mathrm{N}=5, \mathrm{~T}=+15, \mathrm{P}=0.031)$. In the same way, at testing day 6 , the ants were more numerous near the stand bearing 2 elements than near the other stands. These numbers summed for the two colonies and by four over the experimental time equaled 22, 20,15, 14 and 13, while those in front of the stand with one element (located aside that with 2 elements, the second larger count) equaled 4, 8, 7, 2 and 4 respectively. These two numerical series statistically differed $(\mathrm{N}=5, \mathrm{~T}=+15, \mathrm{P}=0.031)$. At testing day 9 , the ants were also more numerous near the stand bearing 2 elements (their successive sums were 21, 26, 10, 12 and 14) than near the stand bearing 3 elements $(5,5,9,6$ and 7$)$. They were still less numerous in the vicinity of the 
other stands. The ants thus essentially chose the stand with the correct sum of elements $(=2)$. At day 12 , the ants of colonies A and B were again more numerous near the stand bearing 2 elements than near the other stands. They were also somewhat numerous in front of the stand bearing one element (and set aside that with 2 elements), but the difference between such a presence and that in front of 2 elements was significant $(\mathrm{N}=5, \mathrm{~T}=+15, \mathrm{P}=0.031)$.

Table 1. Results of experiment I made on colonies A and B for examining if ants could add $1+1$ elements

\begin{tabular}{|c|c|c|c|c|c|c|c|c|c|c|c|c|c|c|c|c|}
\hline \multirow{2}{*}{$\begin{array}{l}\text { Training } \\
\text { days }\end{array}$} & \multicolumn{16}{|c|}{ Mean of 6 daily counts of the ants present near the two presented numbers of elements } \\
\hline & 1 & & 2 & 3 & 4 & & 5 & 6 & 7 & senta & & 9 & 10 & 11 & & 12 \\
\hline colony A & 3.8 & & 6.3 & 6.5 & 3.5 & & .5 & 4.7 & 4.8 & 5 & & 4.3 & 6.3 & 7.5 & & 7.3 \\
\hline colony B & 2.7 & & 3.3 & 3.5 & 4.2 & & 7 & 3.8 & 3.3 & 5 & & 3.7 & 6.3 & 4.7 & & 4.3 \\
\hline Testing & \multicolumn{16}{|c|}{ Mean of 20 counts of the ants approaching each of the four presented numbers of elements } \\
\hline days & \multicolumn{4}{|c|}{3} & \multicolumn{4}{|c|}{6} & \multicolumn{4}{|c|}{9} & \multicolumn{4}{|c|}{12} \\
\hline $\mathrm{n}^{\circ}$ of elements & 1 & 1 & 2 & 3 & 1 & 1 & 2 & 3 & 1 & 1 & 2 & 3 & 1 & 1 & 2 & 3 \\
\hline colony A & 0.5 & 1.2 & 2.4 & 0.8 & 0.1 & 0.7 & 1.5 & 0.6 & 0.1 & 0.8 & 2.4 & 1.0 & 0.3 & 0.5 & 2.0 & 0.1 \\
\hline colony B & 0.3 & 0.5 & 1.3 & 0.8 & 0.2 & 0.6 & 2.8 & 0.4 & 0.1 & 0.8 & 2.3 & 0.6 & 0.2 & 1.0 & 1.5 & 0.3 \\
\hline
\end{tabular}

Details, statistics and means are given in the text. After having been trained to 1 element and 1 element presented side by side near their food, the ants responded essentially to 2 elements when tested in front of 1, 1, 2 and 3 elements. They could thus correctly add $1+1$ elements, and also distinguish 1,2 and 3 elements.

The proportions of correct responses (i.e. responding to 2 elements) at testing days 3, 6, 9 and 12 were $48.0 \%$, $63.2 \%, 58.7 \%$ and $60.5 \%$ respectively. Thus, the ants succeeded to add 1 and 1 elements and to respond to 2 elements with a final score of about $60 \%$.

The 8 mean numbers of ants of the two colonies counted during the four testing days near the stand bearing 2 elements (Table 1, lower part) were statistically higher than the means obtained for the other stands (bearing 1 , or 1 , or 3 elements). The smallest difference was with the ants seen in front of the stand with 1 element located just on the right, and this was already highly significant $(\mathrm{N}=8, \mathrm{~T}=+36, \mathrm{P}=0.004)$. Consequently, the ants obviously chose the correct sum of two elements after having been trained to 1 and 1 elements, already acquiring this notion in 3 days.

Finally, the ants' global responses given during this experiment I to the four presented numbers of elements represented $6.3 \%, 21.3 \%, 56.4 \%$ and $16.0 \%$ of all the responses, for the numbers $1,1,2$ (the correct response) and 3 respectively (Figure 4). This is compared to the ants' global response given during the experiments II, III and IV in the sub-section 'Comparison of experiments I to IV'.

Twenty-four hours after the removal of the stands presented to train the ants, the mean numbers of ants near 1, 1,2 and 3 elements were 1.4, 2.7, 1.6 and 0.7 for colony A, as well as 1.7, 1.6, 1.7 and 0.7 for colony B. The ants were thus no longer more numerous near the stand bearing 2 elements than near the other stands. They were somewhat more numerous near one of the stands bearing 1 element, but this was not statistically different from the ants' presence near the other stand bearing 1 element $(\mathrm{N}=5, \mathrm{~T}=14, \mathrm{P}=0.063)$, and not different from the ants' presence near the stand bearing 2 elements $(\mathrm{N}=4, \mathrm{~T}=10, \mathrm{P}=0.063)$. The ants were the less numerous in front of the stand bearing 3 elements $(\mathrm{N}=5, \mathrm{~T}=-15, \mathrm{P}=0.031)$. Thus, the ants did not memorize the added number of elements and retained only the visual appearance of an element (a blue small square).

\subsection{Experiment II, Ability in Adding $2+1$ Elements}

The trained ants were numerous enough near the two kinds of number of elements presented, for acquiring the memory of these two cues (Table 2, upper part). Meanly 4.39 ones commonly surrounded the two cues.

Concerning the ants' testing (Table 2, lower part; Figure 3, second part), at day 3, the ants seemed to be slightly more numerous in the vicinity of the stand bearing 3 elements than in the vicinity of the three other stands. The numbers of these ants summed for the two colonies and by four over the 10 experimental minutes were $11,13,9$, 10 and 15, while the numbers recorded near the stand with one element (the second larger count) were 1, 7, 13, 7 and 5. The difference between these two series of numbers was just under the limit of significance $(\mathrm{N}=4, \mathrm{~T}=10$, $\mathrm{P}=0.063$ ) and lower than that obtained in the course of the experiment I. At day 6 , the ants were more numerous in front of the stand bearing 3 elements than in front of the other stands. The numbers of ants counted in front of 3 elements and summed by four equaled 20,12,16,12 and 24, while those counted in front of 4 elements equaled 3 , 
4, 5, 8 and 8 , these two series statistically differing $(\mathrm{N}=5, \mathrm{~T}=+15, \mathrm{P}=0.03)$. Thus, after 6 training days, the ants preferred the correctly added number of elements $(2+1=3)$. At day 9 , most of the ants went in front of the stands bearing 3 and 1 elements, being statistically more numerous near the former stand (successive numbers of ants: 11, $17,18,17$ and 15) than near the latter one (successive numbers of ants: $8,9,12,7$ and $3(\mathrm{~N}=5, \mathrm{~T}=15, \mathrm{P}=0.031)$. At day 12, the ants of colonies $\mathrm{C}$ and $\mathrm{D}$ were again more numerous in the vicinity of the stand bearing 3 elements than near the other stands. The differences between such presences and those near 1 as well as 4 elements were significant $(\mathrm{N}=5, \mathrm{~T}=+15, \mathrm{P}=0.031)$.

Table 2. Results of experiment II made on colonies C and D for examining if ants could add $2+1$ elements

\begin{tabular}{|c|c|c|c|c|c|c|c|c|c|c|c|c|c|c|c|c|}
\hline \multirow{2}{*}{$\begin{array}{l}\text { Training } \\
\text { days }\end{array}$} & \multicolumn{16}{|c|}{ Mean of 6 daily counts of the ants present near the two presented numbers of elements } \\
\hline & 1 & & 2 & 3 & 4 & & 5 & 6 & 7 & (2) & & 9 & 10 & 11 & & 12 \\
\hline colony $\mathrm{C}$ & 2.5 & & 2.5 & 3.5 & 4.3 & & .7 & 3.3 & 5.3 & 6 & & 4.7 & 5.5 & 5.7 & & 3.7 \\
\hline colony D & 1.5 & & 3.7 & 3.5 & 4.7 & & .7 & 4.5 & 3.5 & 4 & & 3.7 & 3.7 & 4.3 & & 4.7 \\
\hline Testing & \multicolumn{16}{|c|}{ Mean of 20 counts of the ants approaching each of the four presented numbers of elements } \\
\hline days & \multicolumn{4}{|c|}{3} & \multicolumn{4}{|c|}{6} & \multicolumn{4}{|c|}{9} & \multicolumn{4}{|c|}{12} \\
\hline $\mathrm{n}^{\circ}$ of elements & 2 & 1 & 3 & 4 & 2 & 1 & 3 & 4 & 2 & 1 & 3 & 4 & 2 & 1 & 3 & 4 \\
\hline colony C & 1.2 & 1.2 & 1.8 & 0.5 & 0.1 & 0.5 & 1.6 & 0.9 & 0.7 & 0.9 & 1.6 & 0.1 & 0.1 & 1.1 & 3.9 & 0.9 \\
\hline colony D & 0.4 & 0.6 & 1.4 & 0.1 & 0.9 & 0.7 & 2.6 & 0.6 & 0.1 & 1.1 & 2.4 & 0.1 & 0.1 & 0.8 & 3.6 & 0.9 \\
\hline
\end{tabular}

Details, statistics and means are given in the text. After having been trained to 2 elements and 1 element set side by side near their food, the ants responded essentially to 3 elements when tested in front of 2, 1, 3, and 4 elements. They could thus distinguish these 2, 1, 3 and 4 elements, and correctly add $2+1$ elements $=3$ elements.

The proportions of correct responses (choosing the stand bearing 3 elements) at testing days 3, 6, 9 and 12 were $44.7 \%, 54.2 \%, 56.1 \%$ and $66.7 \%$ respectively. Thus, they could add 2 and 1 elements and respond to the correct sum of 3 elements with a final score of about $67 \%$.

The 8 mean numbers of ants of the two colonies counted at each four testing days near the stand bearing 3 elements (Table 2, lower part) were statistically higher than those corresponding to the other stands (bearing 2, or 1, or 4 elements). The smallest difference was that with the means corresponding to the ants seen in front of 1 element, and this smallest difference was already statistically significant $(\mathrm{N}=8, \mathrm{~T}=+36, \mathrm{P}=0.004)$. Consequently, the ants correctly selected the sum of 3 elements, acquiring such a notion in about 6 days.

Finally, the ants' global responses given to $2,1,3$ (the correct response) and 4 elements were $10.7 \%, 20.6 \%, 56.4 \%$, and $12.2 \%$ respectively (Figure 4 ). These proportions are compared to those obtained for the experiments I, III and IV in the sub-section 'Comparison of experiments I to IV'.

Twenty-four hours after the removal of the stands presented for training, the ants were no longer more numerous in front of the stand bearing 3 elements. Indeed, the mean ant numbers seen in front of 2, 1, 3 and 4 elements were, for colony $\mathrm{C} 1.1,1.4,1.2$ and 0.3 , and for colony $\mathrm{D}, 0.6,1.3,1.0$ and 1.2. The ants were somewhat more numerous in front of 1 element: this slightly higher presence differed from that in front of two elements $(\mathrm{N}=5, \mathrm{~T}=15, \mathrm{P}=$ $0.031)$, but not from that in front of 3 elements $(\mathrm{N}=5, \mathrm{~T}=+11,-4, \mathrm{P}=0.219)$. The ants' lowest presence was that in front of 4 elements, which differed from that in front of 1 and 3 elements $(\mathrm{N}=5, \mathrm{~T}=15, \mathrm{P}=0.031)$, but not from that in front of two elements $(\mathrm{N}=5, \mathrm{~T}=+5,-10, \mathrm{P}=0.313)$. Consequently, the ants did not remember what they previously learned.

\subsection{Experiment III, Ability in Adding $3+1$ Elements}

During training, the ants were numerous enough near the two kinds of presented numbers for becoming able to remember these two numbers (Table 3, upper part). There were indeed meanly 6.4 ants near these two numbers.

When tested at day 3 , the ants appeared to be more numerous in front of the stand bearing 4 elements than in front of the other stands (Table 3, lower part; Figure 3, third part). They were also somewhat numerous in front of the stand bearing 5 elements, and not in front of the other stands. However, the numbers of ants of the two colonies approaching the stand with 4 elements, summed by four, were 11, 14, 9, 12 and 8 , while those recorded for the stand with 5 elements were $5,4,1,6$ and 4 , two series of numbers statistically differing $(\mathrm{N}=5, \mathrm{~T}=15, \mathrm{P}=0.031)$. At day 6, the ants went preferentially in front of the stand bearing 4 elements: their numbers, added by four over the experimental time, equaled $15,15,16,13$ and 12 . The second more visited stand was that bearing 5 elements: 
the numbers of ants counted there over the 10 experimental minutes and summed by four were 2, 6, 3, 6 and 5 . These two series statistically differed $(\mathrm{N}=5, \mathrm{~T}=15, \mathrm{P}=0.031)$, the ants reacting thus correctly essentially to 4 elements. At day 9, the ants again went preferentially to the stand bearing 4 elements, the numbers of them, summed by four over the experimental time, equaling $11,16,11,12$ and 12 . The second stand the more visited was that bearing 5 elements, the numbers of ants summed by four over the experimental time being 5, 2, 5,8 and 8 . The two series of ant numbers statistically differed $(\mathrm{N}=5, \mathrm{~T}=15, \mathrm{P}=0.031)$, the ants having thus correctly essentially reacted to 4 elements. At day 12, the ants again essentially reacted to 4 elements and, at a lower extent, to 5 elements, the numbers of reacting ants, summed by four over the experimental time, equaling for 4 elements 22,22 , $14,15,19$ and for 5 elements, $7,12,7,6,7$. These two series of ant numbers statistically differed $(\mathrm{N}=5, \mathrm{~T}=15, \mathrm{P}$ $=0.031)$, the ants having thus once more correctly reacted the most to 4 elements.

Table 3. Results of experiment III made on colonies E and F for examining if ants could add $3+1$ elements

\begin{tabular}{|c|c|c|c|c|c|c|c|c|c|c|c|c|c|c|c|c|}
\hline \multirow{2}{*}{$\begin{array}{l}\text { Training } \\
\text { days }\end{array}$} & \multicolumn{16}{|c|}{ Mean of 6 daily counts of the ants present near the two presented numbers of elements } \\
\hline & 1 & & 2 & 3 & 4 & & 5 & 6 & 7 & 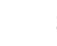 & & 9 & 10 & 11 & & 12 \\
\hline colony $\mathrm{E}$ & 6.3 & & 5.5 & 6.8 & 7.5 & & .5 & 6.3 & 7.2 & 7 & & 8.3 & 9.2 & 6.3 & & 4.5 \\
\hline colony $\mathrm{F}$ & 8.0 & & 5.3 & 5.3 & 4.8 & & .5 & 5.7 & 5.5 & 5 & & 5.3 & 5.7 & 5.8 & & 7.7 \\
\hline Testing & \multicolumn{16}{|c|}{ Mean of 20 counts of the ants approaching each of the four presented numbers of elements } \\
\hline days & \multicolumn{4}{|c|}{3} & \multicolumn{4}{|c|}{6} & \multicolumn{4}{|c|}{9} & \multicolumn{4}{|c|}{12} \\
\hline $\mathrm{n}^{\circ}$ of elements & 3 & 1 & 4 & 5 & 3 & 1 & 4 & 5 & 3 & 1 & 4 & 5 & 3 & 1 & 4 & 5 \\
\hline colony E & 0.2 & 0.4 & 1.4 & 0.6 & 0.1 & 0.4 & 1.5 & 0.5 & 0.6 & 0.4 & 2.0 & 0.8 & 0.5 & 0.7 & 2.7 & 1.1 \\
\hline colony $\mathrm{F}$ & 0.2 & 0.5 & 1.4 & 0.4 & 0.0 & 0.7 & 2.1 & 0.7 & 0.2 & 0.4 & 1.7 & 1.7 & 0.8 & 1.1 & 4.6 & 2.0 \\
\hline
\end{tabular}

Details, statistics and means are given in the text. After having been trained to 3 elements and 1 element presented side by side near their food, the ants, tested in front of 3, 1, 4 and 5 elements went essentially towards 4 elements, and to a lower extent, to 5 elements. They thus correctly added $3+1=4$.

The proportions of correct responses obtained at testing days 3, 6, 9 and 12 were $56.1 \%, 60.2 \%, 54.5 \%$ and $54.7 \%$ respectively. Thus, the ants reacted correctly to 4 elements with a score of about $55 \%$.

Looking to the 8 mean numbers of ants obtained for the two colonies and the four conducted experiments (Table 3 ) shows that the higher ones concerned the ants' choice of 4 elements. The smallest difference was between these higher mean values and those concerning the ants' choice of 5 elements, and even this smallest difference was statistically significant $(\mathrm{N}=7, \mathrm{~T}=28, \mathrm{P}=0.008)$. Consequently, the ants reacted statistically the most to the correct sum of 4 elements throughout all the experiments.

The ants' global responses given to 3, 1, 4 (correct response) and 5 elements were $8.1 \%, 14.3 \%, 54.2 \%$, and $24.3 \%$ respectively (Figure 4), what is compared to corresponding results obtained for experiments I, II and IV in the sub-section 'Comparison of experiments I to $I V$ '.

Twenty-four hours after the removal of the stands used for training, the ants reacted essentially to 1 element and to 4 elements, the mean ant numbers for colony E being $0.3,1.4,1.4,0.9$ and for colony F $0.2,1.3,1.1,0.1$, for 3,1 , 4 and 5 elements respectively. The numbers of ants of the two colonies summed by four over the 10 experimental minutes were 13,13, 9, 11, 8 for the stand with 1 element, and 7,12,10,14, 6 for the stand with 4 elements, two series statistically similar $(\mathrm{N}=5, \mathrm{~T}=-8,+7, \mathrm{P}=0.50)$. Thus, the ants went on reacting to the element 'a small blue square', but no longer to the correct sum (i.e. $3+1=4$ ).

\subsection{Experiment IV, Ability in Adding $3+2$ Elements}

During training, meanly 5.6 ants of the two used colonies approached the two presented stands bearing two different numbers (Table 4, upper part). They ants had thus sufficiently the occasion to learn these two numbers of elements (i.e. 3 and 2 elements).

When tested at day 3 , the ants seemed approaching more often the stand bearing 4 elements than the other stands (Table 4, lower part; Figure 3, last part). They also somewhat approached the stand bearing 5 elements. However, the numbers of ants counted in front of 4 elements and summed by four equaled 17, 19,18, 19 and 14, while those of ants approaching 5 elements equaled 10,10,10,10 and 9 . These two series of recorded numbers statistically differed $(\mathrm{N}=5, \mathrm{~T}=15, \mathrm{P}=0.031)$. The ants responded thus more to 4 elements than to 5 elements and, a fortiori, than to 3 and 2 elements. When tested at day 6 , the ants were more numerous in front of the stand bearing 5 
elements. The second more visited stand was that bearing 6 elements. The numbers of ants counted in front of 5 elements and 6 elements, summed by four, equaled 20,18,18,15, 15 and 4, 6, 7, 8, 7 respectively, two series of numbers statistically differing $(\mathrm{N}=5, \mathrm{~T}=15, \mathrm{P}=0.031)$. The ants thus correctly reacted essentially to 5 elements. At day 9 , the ants essentially moved again towards the stand bearing 5 elements, and moved also but less towards the stand bearing 6 elements. The ant numbers, summed by four over the 10 experimental minutes, equaled 20,12, 18,11 and 13 in the former case, and 5, 4, 9, 8 and 8 in the latter case. These two series statistically differed $(\mathrm{N}=5$, $\mathrm{T}=15, \mathrm{P}=0.031$ ), the ants having thus essentially responded to the correct sum of 5 elements. At day 12 , the ants once more reacted essentially to 5 elements and, at a lower extent, to 6 elements, the numbers of these reacting ants, summed by four over the 10 experimental minutes, equaling $11,15,14,16,15$ for 5 elements, and 6, 8, 7, 8, 9 for 6 elements. These two series statistically differed $(\mathrm{N}=5, \mathrm{~T}=15, \mathrm{P}=0.031)$, the ants having thus essentially responded to 5 elements.

Table 4. Results of experiment IV made on colonies $\mathrm{G}$ and $\mathrm{H}$ for examining if ants could add $3+2$ elements

\begin{tabular}{|c|c|c|c|c|c|c|c|c|c|c|c|c|c|c|c|c|}
\hline \multirow{2}{*}{$\begin{array}{l}\text { Training } \\
\text { days }\end{array}$} & \multicolumn{16}{|c|}{ Mean of 6 daily counts of the ants present near the two presented numbers of elements } \\
\hline & 1 & & 2 & 3 & 4 & & 5 & 6 & 7 & $\delta$ & & 9 & 10 & 11 & & 12 \\
\hline colony G & 3.5 & & 6.3 & 4.7 & 4.7 & & .2 & 6.3 & 6.5 & 5 & & 5.7 & 5.0 & 4.8 & & 4.5 \\
\hline colony $\mathrm{H}$ & 4.3 & & 4.7 & 4.5 & 4.8 & & .7 & 6.3 & 6.7 & 5 & & 6.5 & 7.0 & 6.5 & & 6.5 \\
\hline Testing & \multicolumn{16}{|c|}{ Mean of 20 counts of the ants approaching each of the four presented numbers of elements } \\
\hline days & \multicolumn{4}{|c|}{3} & \multicolumn{4}{|c|}{6} & \multicolumn{4}{|c|}{ 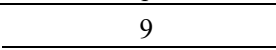 } & \multicolumn{4}{|c|}{12} \\
\hline $\mathrm{n}^{\circ}$ of elements & 3 & 2 & 5 & 6 & 3 & 2 & 5 & 6 & 3 & 2 & 5 & 6 & 3 & 2 & 5 & 6 \\
\hline colony G & 0.3 & 0.8 & 1.4 & 0.9 & 0.3 & 0.8 & 1.8 & 0.8 & 0.0 & 0.7 & 2.7 & 1.1 & 1.0 & 0.2 & 1.6 & 1.1 \\
\hline colony $\mathrm{H}$ & 0.2 & 1.0 & 3.0 & 1.6 & 1.0 & 0.7 & 2.5 & 0.8 & 0.3 & 0.3 & 1.5 & 0.7 & 0.1 & 1.0 & 2.0 & 0.9 \\
\hline
\end{tabular}

Details, statistics and means are given in the text. After having been trained to 3 elements and 2 elements deposited side by side near their food, the ants tested in front of 3,2,5 and 6 elements essentially moved to 5 elements, and at a lower extent, to 6 elements, having thus correctly made the addition $3+2=5$.

The proportions of correct responses given by the ants of the two colonies at testing days 3, 6, 9 and 12 equaled $48.6 \%, 49.7 \%, 57.6 \%$ and $46.1 \%$ respectively. Therefore, the ants gave the correct response ' 5 elements' with a mean score of about $50 \%$.

A look to the 8 mean numbers of ants obtained for the two colonies during the four experiments (Table 4) shows that the higher mean numbers were those relative to 5 elements, and that the secondly higher ones were those relative to 6 elements. Even the small difference between these two higher mean numbers was statistically significant $(\mathrm{N}=8, \mathrm{~T}=36, \mathrm{P}=0.004)$. Consequently, the ants have mostly responded to 5 elements, having thus visually added the 3 and 2 elements seen during training.

The global responses given by ants to 3, 2, 5 (the correct response) and 6 elements represented $9.7 \%, 16.6 \%$, $49.8 \%$, and $23.9 \%$ respectively (Figure 4 ). This is compared to what was obtained for experiments I, II and III in the sub-section 'Comparison of experiments I to $I V$ '.

Twenty-four hours after the removal of the stands used for training, the ants reacted essentially to 2 elements and to 5 elements, the mean ant numbers for colony $\mathrm{G}$ being 1.0, 1.3, 1.3, 0.9 and for colony $\mathrm{H} 0.4,1.1,2.0,1.2$ for 3,2 , 5 and 6 elements respectively. The numbers of ants of the two colonies summed by four over the 20 experimental minutes were 12,12,16,13,11 for the stand with 2 elements, and 12, 6, 12,11, 7 for the stand with 5 elements, two series which did not (or only very slightly) statistically differ $(\mathrm{N}=4, \mathrm{~T}=10, \mathrm{P}=0.063)$. Thus, the ants went on reacting to the element 'a small blue square', but no longer strongly to the correct sum $3+2=5$ of such blue squares.

\subsection{Comparison of Experiments I to IV}

This comparison is graphically shown in Figure 4. In presence of 1 and 1 elements, as well as of 2 and 1 elements, the ants gave the correct response with a global score of $56.4 \%$, and responded also to 1 element with a score of about $21 \%$. In presence of 3 and 1 elements, the ants gave the correct response with a score of $c a 54 \%$, and reacted also to 5 elements with a score of $c a 24 \%$. Effectively, the visual difference between 4 and 5 elements is small. In presence of 3 and 2 elements, the ants gave the correct response with a score of $c a 50 \%$, and reacted also to 6 elements with a score of $\mathrm{ca} 24 \%$. Effectively, the visual difference between 5 and 6 elements was slight. 
Consequently, the ants could visually add identical elements seen at the same time side by side, and seemed to do so less well as the number of elements increased.

\section{Discussion-Conclusion}

Having previously shown that the workers of the ant Myrmica sabuleti have a basic notion of 'zero' (= nothing) (Cammaerts \& Cammaerts, 2019a, b) and knowing that they can distinguish different numbers of elements (Cammaerts, 2008), we here examined if they can also add two numbers of identical elements. The notion of numbers precedes that of zero in the humans' life and history and in the animals' evolution (Fuson, 1988; Michelot, 1966). The ability of adding can also be acquired before the mathematical concept of zero (e.g. Greeks and Romans could add but never used a symbol for 'zero').

We found that trained at the same time to 1 and 1 elements, 2 and 1 elements, 3 and 1 elements, 3 and 2 elements, M. sabuleti workers thereafter reacted essentially to 2, 3, 4 and 5 elements respectively, having thus correctly reacted to the addition of the two numbers of elements presented during training. Such a result confirms our previous finding of the M. sabuleti workers' ability in distinguishing different numbers of elements (Cammaerts, 2008), and it somewhat enlarges what is known about the cognition of the species and its limits. Let us however remark that, during experiments III and IV, the ants reacted essentially to the correct added numbers equaling 4 and 5 elements respectively, but, among the three possible wrong responses, they responded the more to the correct added numbers of elements plus one element, i.e. 5 and 6 elements respectively. This kind of response did not occur during experiments I and II. Thus, for these ants, distinguishing different numbers of elements may become increasingly difficult when the number of elements enlarges, an observation also made in monkeys (Hauser et al., 2000).

The ants have been here trained in the presence of two numbers of elements to be added, what was at the same level as what was done on an elephant (one single individual) (e.g. Irie, Hiraiwa-Hasegawa, \& Kutsukake, 2019), but what differed from what has been done on robins and several monkeys (Garland \& Low, 2014; Flombaum, Junge, $\&$ Hauser, 2005; Beran, 2008). The latter animals were confronted to one number of elements (visual, olfactory or acoustic cues), then with another number of identical elements, and they could later react to the correctly added numbers of elements. In other words, during such complex experiments, the trained individuals were never confronted at the same time to the numbers of elements they should add, while during our experiment, the trained ants were simultaneously confronted to two numbers to add. A future research should examine if ants could add numbers of identical elements when they see them consecutively (i.e. when they see a second set of elements a short time after having seen a first set).

What has been done in the present work looks like the learning of adding by young children: they are presented at the same time with two numbers of objects (often of two different colors) and must find the sum. However, later on, they progressively learn to add several numbers of elements without necessarily seeing them at the same time. What was done in the present work may also approach, but at a quantitative level, the bees' qualitative perception of two different odors and to their subsequent reaction to a mixture of the two odors, another part of their brain being then active (Guerrieri, 2005). Note that for vertebrates also, the cerebral part active when responding to the sum of two numbers of elements differs from the two cerebral parts active when perceiving separately the two numbers elements (Nieder, Freedman, \& Miller, 2002).

We know that $M$. sabuleti workers have a basic, visual and olfactory, notion of zero. Do they consider the zero not only as 'an absence' a 'not presence' a 'nothing', but also as an element at the start of an increasing series of elements and at the end of a decreasing series of elements? Future experiments will tempt to answer this question.

In conclusion, $M$. sabulet $i$ workers have the notion of numbers and the basic concrete notion of zero, and they can add different numbers of identical elements when they perceive them at the same time. This might be the limit of their cognition. It remains to examine if they can add numbers of elements when seeing them not simultaneously but consecutively (one then another one, in any order), and if they consider the zero as being less than one element.

\section{Ethics}

We affirm having maintained the ants in the laboratory under the best possible condition. We also affirm having no conflict of interest concerning the examined topic, and having received no money for conducting our research.

\section{Conflict of interests}

The authors declare that there is no conflict of interests regarding the publication of this paper. 


\section{References}

Agrillo, C., Dadda, M., Serena, G., \& Bisazza, A. (2008). Do fish count? Spontaneous discrimination of quantity in female mosquitofish. Animal Cognition, 11(3), 495-503.

Beran, M. J. (2008). Monkeys (Macaca mulatta and Cebus apella) track, enumerate, and compare multiple sets of moving items. Journal of Experimental Psychology: Animal Behavior Processes, 34(1), 63-74.

Brannon, E., Herbert, M., \& Terrace, S. (1988). Ordering of the Numerosities 1 to 9 by Monkeys. Science, New Series, 282(5389), 746-749.

Cammaerts, M. C. (2008). Visual discrimination of cues differing as for their number of elements, their shape or their orientation, by the ant Myrmica sabuleti. Biologia, 63, 1169-1180.

Cammaerts, M. C., \& Cammaerts, R. (2019a). Ants are at the first stage of the notion of zero. International Journal of Biology, 11(1), 54-65.

Cammaerts, M. C., \& Cammaerts, R. (2019b). Ants' notion of zero through the perception of the absence of an odor. International Journal of Biology, 11(2), 1-12.

Church, R. M., \& Meck, W. H. (1984). The numerical attribute of stimuli. In H. L. Roitblat, T. G. Bever, \& H. S. Terrace (Eds.), Animal Cognition (pp. 445-464). ISBN: 978-0898593341.

Flombaum, J. I., Junge, J. A., \& Hauser, M. D. (2005). Rhesus monkeys (Macaca mulatta) spontaneously compute addition operations over large numbers. Cognition, 97, 315-325.

Fuson, K. C. (1988). Children's counting and concepts of number. New York: Springer-Verlag. Retrieved from https://www.springer.com/la/book/9781461283355

Garland, A., \& Low, J. (2014). Addition and subtraction in wild New Zealand robins. Behavioural Processes, 109, 103-110.

Guerrieri, F. (2005). Une étude intégrative de la perception olfactive chez l'abeille Apis mellifera: Comportement et imagerie calcique. Thesis (University of Toulouse, France). 10.13140/RG.2.2.15828.403231.

Hauser, M. D., Carey, C., \& Hauser, B. (2000). Spontaneous number representation in semi-free-ranging rhesus monkeys. Proceedings of the Royal Society of London B, 267, 829-833.

Howard, S. R., Avarguès-Weber, A., Garcia, J. E., Greentree, A. D., \& Dyer, A. G. (2018). Numerical ordering of zero in honey bees. Science, 360(6393), 1124-1126.

Hunt, S., Low, J., \& Burns, K. (2008). Adaptive numerical competency in a food-hoarding songbird. Proceedings of the Royal Society B: Biological Sciences, 275(1649), 2373-2379.

Irie, N., Hiraiwa-Hasegawa, M., \& Kutsukake, N. (2019). Unique numerical competence of Asian elephants on the relative numerosity judgment task. Journal of Ethology, 37, 111-115.

Matsuzawa, T. (2009). Symbolic representation of number in chimpanzees. Current Opinion on Neurobiology, 19 , 92-98. Retrieved from https://langint.pri.kyoto-u.ac.jp > ... > Tetsuro Matsuzawa

Michelot, A. (1966). La notion de zéro. In 'L'enfant' a collection directed by Chateau J. Vrin J. Paris. Retrieved from http://www.vrin.fr/book.php?code=9782711605705

Nieder, A., Freedman, D. J., \& Miller, E. K. (2002). Representation of the quantity of visual items in the primate prefrontal cortex. Science, 297(5587), 1708-1711.

Pepperberg, I. M. (2006) Grey parrot numerical competence: A review. Animal Cognition, 9(4), 377-391. Retrieved from http://psycnet.apa.org/record/2007-07451-012

Pepperberg, I. M., \& Gordon, J. D. (2005). Number comprehension by a grey parrot (Psittacus erithacus), including a zero-like concept. Journal of Comparative Psychology, 119(2), 197-209.

Range, F., Jenikejew, J., Schröder, I., \& Virányi, Z. (2014). Difference in quantity discrimination in dogs and wolves. Frontiers in Psychology, 5, 1299.

Rose, G. J. (2018). The numerical abilities of anurans and their neural correlates: Insights from neuroethological studies of acoustic communication. Philosophical Transactions of the Royal Society B: Biological Sciences, 373.

Rugani, R., Vallortigara, G., Priftis, K., \& Regolin, L. (2015). Number-space mapping in the newborn chick resembles humans' mental number line. Science, 347(6221), 534-536. 
Siegel, S., \& Castellan, N. J. (1989). Nonparametric statistics for the behavioural sciences. Singapore, McGraw-Hill Book Company. Retrieved from https://www.amazon.com/Sidney-Siegel...Statistics.../B008W DIR6

Woodruff, G., \& Premack, D. (1981). Primative [sic] mathematical concepts in the chimpanzee: Proportionality and numerosity. Nature, 293(5833), 568-570.

Xia, L., Sieman, M., \& Delius, J. D. (2000). Matching of numerical symbols with number of responses by pigeons. Animal Cognition, 3, 35-43.

\section{Copyrights}

Copyright for this article is retained by the author(s), with first publication rights granted to the journal.

This is an open-access article distributed under the terms and conditions of the Creative Commons Attribution license (http://creativecommons.org/licenses/by/4.0/). 